\title{
Postoperative Skin Complications after Spine Surgery in the Prone Position
}

\author{
Ali Baradaran Bagheri ${ }^{1,}$ Leila Sadati $^{2 *}$, Alireza Beyrami ${ }^{2}$, Sajad Fatollahi ${ }^{3}$, Zahra Nouri Khanegah ${ }^{2}$, \\ Hojjat Torkamandi ${ }^{2}$
}

1. Department of Neurosurgery, School of Medicine, Alborz University of Medical Sciences, Karaj, Iran

2. Operating Room Department, Faculty of Paramedicie, Alborz University of Medical Sciences, Karaj, Iran

3. Imam Khomeyni Hospital, Tehran University of Medical Sciences, Tehran, Iran

\begin{abstract}
Background and objectives: One of the adverse effects of prone positioning in spine surgery is the occurrence of skin damage. Due to the high rate of spine surgeries and the frequent use of prone positioning during these procedures, we aimed to investigate postoperative skin complications after spine surgery in the prone position.

Methods: This descriptive cross-sectional study was performed in 2016-2017 on 160 patients undergoing spine surgery in the prone position at a teaching hospital in Tehran, Iran. The patients' body parts were examined for presence any redness, ecchymosis and pressure ulcers before discharge from the hospital. Collected data were analyzed in SPSS software (version 19) using descriptive statistics, Chi-square test, Mann-Whitney U test and Kendall's correlation coefficient.

Results: Almost all patients had skin damage, especially redness, in the postoperative stage. Age, gender, duration of surgery, height, weight and body mass index were significantly associated with incidence of skin damage $(\mathrm{P}<0.05)$.

Conclusion: Our results indicated that the incidence of postoperative skin damage is relatively high in patients undergoing spine surgery in the prone position. Therefore, it is recommended to take appropriate precautions in order to prevent these complications.
\end{abstract}

Keywords: Skin damages; Spine surgery; Prone position

\section{$\begin{array}{lll}\text { Received: 2019/09/27 } & \text { Revised:2019/10/09 } & \text { Published:2019/10/17 }\end{array}$}

*Correspondence: Leila Sadati, Operating Room Department, Faculty of Paramedicie, Alborz University of Medical Sciences, Karaj, Iran

Tel: +98-2634349807

Email: sadati@abzums.ac.ir 


\section{INTRODUCTION}

Proper positioning of the patient in the operating room is of great importance for ensuring the patient's safety during the surgery and preventing skin damage and mechanical stress on the patient's body, and thus allowing proper exposure for surgery, airway management and proper monitoring by the anesthesia team $(1,2)$. Establishing a safe position for patients requires knowledge and awareness about the anatomy and physiology of the body, as well as familiarity with the equipment necessary for positioning. In addition, several factors such as cardiovascular status, age, height, weight and the type of surgery should be considered when establishing a safe position (2). Operating room nurses, as part of the surgical team, are responsible for planning and providing appropriate care interventions for proper positioning and to secure patients' comfort and safety (1).

Spine surgery is one of the most common surgical procedures performed in the United States (3). In order to access the spine, the surgical team uses several positions including the prone, knee-chest and lateral positions, each with its own limitations and care considerations (4). The prone position is commonly used in spine surgery mainly through the Wilson and Andrews frames (5). These frames are used to position the patient in a modified knee-chest position, which increases the intralaminar distance and facilitates access to the spinal canal during decompression procedures by creating a kyphosis-like position in the lumbar spine and adjustable curvature for any degree of flexion extension (6). Due to the precarious nature of prone positioning, injuries such as compartment syndrome, peripheral neuromuscular neuropraxia, pressure injuries, posterior ischemic optic neuropathy, facial contact pressure, increase of intraocular pressure and cardiovascular complications are well described after neurologic surgery (7). Shaw et al. observed development of stage 1 pressure ulcers in $9.8 \%$ of patients, immediately after surgery and in $5.1 \%$ of patients within 30 minutes of surgery (8). In another study, Scott described some of the main preoperative (age, comorbidities, and nutritional status) and intraoperative (blood loss, anesthesia type, length of surgery, positioning, hypothermia, hypotension, use of devices, draping, and place surgical patients) risk factors of perioperative pressure ulcer (9). Despite the low prevalence of some of these complications, one should not undermine the importance of such complications and its severe impact on patients, their families, and ultimately on their quality of life. Therefore, identifying these complications and their causes, as well as the situations under which each may occur can prove beneficial in taking preventive measures and improving patients' satisfaction $(10,11)$. In this study, we investigate postoperative skin complications after spine surgery in the prone position.

\section{MATERIALS AND METHODS}

This descriptive cross-sectional study was performed in 2016-2017 on 160 patients (60 men and 100 women) undergoing spine surgery in the prone position at a teaching hospital in Tehran, Iran. The subjects were selected through census. Inclusion criteria included having no previous skin conditions, no ocular problems, having spinal deformities and neuropathy, and a surgical duration of 1 to 4 hours. Meanwhile, patients affected by intraoperative complications or reluctant to participate in this study were excluded. Informed consent was obtained from all eligible candidates prior to participation in the study.

A researcher-made questionnaire was designed to collect data on demographic information and skin complications. Items of the survey were determined by reviewing relevant literature and opinions of a panel of experts. Content validity of the survey was assessed by the panel of experts. In addition, a content validity index of 0.83 and a content validity ratio of 0.89 were calculated for the survey. Reliability of the instrument was 
confirmed using the inter-rater agreement (percent agreement: 81\%).

After obtaining the necessary permissions and approval from the ethics committee of the Alborz University of Medical Sciences (Abzums.REC.1395,43), the researchers visited the operating room and filled out the first part of the questionnaire, i.e. demographic information, for each patient in the surgery waiting room. The researchers examined the patient's body parts for presence of any redness, ecchymosis and pressure ulcers before discharge from the hospital. Collected data were analyzed in SPSS software (version 19) using descriptive statistics and Chi-square test, Mann-Whitney U test and Kendall's correlation coefficient.

\section{RESULTS}

The mean age of patients was $53.84 \pm 12.29$ years. The mean body mass index (BMI) of patients was $27.5 \pm 4 \mathrm{~kg} / \mathrm{m}^{2}$, and the mean duration of surgery was $2.69 \pm 0.53$ hours.

Figures 1 shows the frequency of redness, ecchymosis and pressure ulcer in different body parts. The frequency of skin damage in the hip area was higher in women $(67 \%)$ than in men $(41.3 \%)$, while damage in the genital area was more common in men $(31.7 \%)$ than in women (6\%). Moreover, facial skin damage was only observed in men (15\%).

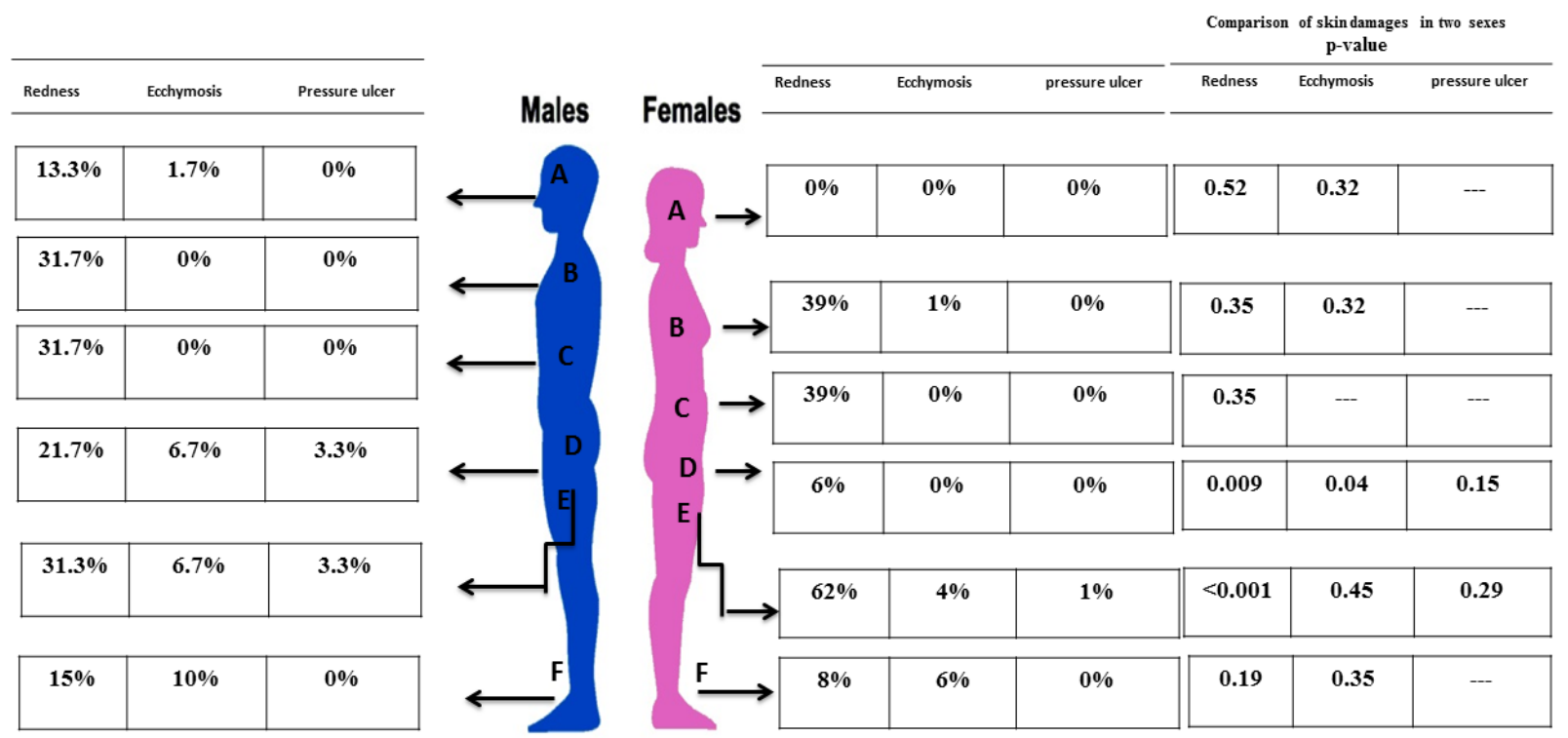

Figure 1. Frequency of skin lesions in different body parts (A: Face, B: Thorax, C: Abdomen, D: Genital, E: Hip, F: Ankle) of the patients after spine surgery in the prone position.

Table 1 shows the relationship between characteristics of the patients and incidence of skin damage in different body parts. Based on the results, redness of hip was significantly more common in women (P-value=0.001), while redness of genital area was significantly more common in men (P-value=0.005). Redness of ankle was significantly more common in taller patients (Pvalue $=0.001$ ), and redness of face was significantly more common in higherweight patients $(\mathrm{P}$-value $=0.01)$. Redness of abdomen was significantly more common in older patients (Pvalue $=0.01$ ). Furthermore, there was a significant correlation between pressure ulcers of ankle and duration of surgery (Table 1). 
Journal of Clinical and Basic Research (JCBR). 2019; 3(3): P 18-24.

Table 1. The relationship between demographic characteristics of the patients and skin damage in different parts of body in the prone position

\begin{tabular}{|c|c|c|c|c|c|c|c|}
\hline \multirow{3}{*}{ Body part } & Skin damage & \multicolumn{6}{|c|}{ P-Value } \\
\cline { 3 - 8 } & & Age & Sex & Height & Weight & BMI & $\begin{array}{c}\text { Surgery } \\
\text { duration }\end{array}$ \\
\hline \multirow{3}{*}{ Hip } & Redness & 0.23 & 0.001 & 0.06 & 0.03 & 0.002 & 0.25 \\
\cline { 2 - 8 } & Ecchymosis & 0.07 & 0.34 & 0.67 & 0.25 & 0.53 & 0.82 \\
\cline { 2 - 8 } Ankle & Pressure ulcers & 0.11 & 0.03 & 0.1 & 0.015 & 0.04 & 0.15 \\
\hline & Redness & 0.82 & 0.19 & 0.001 & 0.1 & 0.054 & 0.63 \\
\cline { 2 - 8 } & Ecchymosis & 0.32 & 0.36 & 0.11 & 0.32 & 0.063 & 0.98 \\
\cline { 2 - 8 } Face & Pressure ulcers & 0.12 & 0.07 & 0.03 & 0.02 & 0.04 & 0.006 \\
\hline \multirow{3}{*}{ thorax } & Redness & 0.03 & 0.02 & 0.36 & 0.01 & 0.08 & 0.02 \\
\cline { 2 - 8 } & Ecchymosis & 0.57 & 0.37 & 0.45 & 0.22 & 0.48 & 0.41 \\
\cline { 2 - 8 } & Pressure ulcers & 0.07 & 0.04 & 0.11 & 0.06 & 0.05 & 0.05 \\
\hline & Redness & 0.06 & 0.02 & 0.11 & 0.01 & 0.03 & 0.02 \\
\cline { 2 - 8 } & Ecchymosis & 0.01 & 0.07 & 0.14 & 0.22 & 0.83 & 0.18 \\
\hline \multirow{3}{*}{ Genitals } & Pressure ulcers & 0.15 & 0.06 & 0.09 & 0.05 & 0.05 & 0.05 \\
\cline { 2 - 8 } & Redness & 0.01 & 0.041 & 0.91 & 0.038 & 0.049 & 0.03 \\
\cline { 2 - 8 } & Ecchymosis & 0.08 & 0.34 & 0.16 & 0.08 & 0.5 & 0.28 \\
\cline { 2 - 8 } & Pressure ulcers & 0.41 & 0.03 & 0.64 & 0.02 & 0.05 & 0.015 \\
\cline { 2 - 8 } & Eedness & 0.89 & 0.005 & 0.06 & 0.002 & 0.02 & 0.003 \\
\cline { 2 - 8 } & Ecchymosis & 0.73 & 0.019 & 0.31 & 0.15 & 0.30 & 0.28 \\
\hline
\end{tabular}

\section{DISCUSSION}

The present study aimed to investigate the incidence of skin damage in various body parts caused by prone positioning in spine surgery. Almost all patients had skin damage, especially redness, in the postoperative stage. According to AORN's Guidelines for patient positioning, the incidence of pressure ulcers resulted from surgery may be as high as $66 \%$ (12). In our study, $7.6 \%$ of the cases had pressure ulcers and skin tissue degeneration. Other studies reported the incidence of postoperative pressure ulcers to be less than $2 \%(13,14)$. The high rate of pressure ulcers in our subjects could be due to the inappropriate implementation of standard safety guidelines during surgery in the prone position, such as using pillows instead of standard pads. In addition, surgery duration of longer than 2 hours may increase the risk of developing pressure ulcers (12). Despite the recommendation of AORN for patient repositioning every two hours, this type of care is not implemented during neurosurgical procedures, which could be a contributing factor for the increased rate of pressure ulcers in the postoperative period.
Several factors such as age, gender, surgery duration, weight, height and BMI are thought to influence the risk of postoperative skin damage $(12,15-19)$. In the present study, surgery duration had a significant relationship with incidence of facial redness. This finding is in line with results of studies by O'Connell (5) and Schouchoff (20). However, Bulfone et al. reported a very low risk of skin damage in patients undergoing surgeries shorter than 90 minutes. Extending the duration of surgery to 2.5-4 hours leads to a 2-fold increase in the risk of skin damage. If the surgery lasts longer than 4 hours, the risk of skin damage may increase up to three times (21). Our results indicated a significant relationship between facial redness and surgery duration in men, which seems to be due to negligence of the care personnel in using protection pads.

In our study, the incidence of skin damage increased with age. During the aging process, skin elasticity, muscle strength, collagen content and the amount of subcutaneous fat tissues decrease which consequently impair blood supply to the tissues, thus increasing skin susceptibility to damage (22). In line 
with our results, several studies have shown that the risk of skin damage in patients undergoing surgery increases with age (2326). Furthermore, we found a significant relationship between BMI and weight and the incidence of skin damage under pressure. This is consistent with findings of previous studies (12, 27, 28). It seems that using thicker protective pads in areas under pressure for obese patients could reduce the risk and extent of skin damage.

We found that skin damage in the thoracic and hip areas was more common in women than in men. In this regard, two previous studies also reported that women are more susceptible to developing postoperative skin damage, particularly in the thoracic area (29, 30). On the other hand, the genital area of men are more likely to suffer from skin damage compared with women, which can be due to the anatomical differences between the two genders as well as the unavailability of anatomic pads specifically designed for men's genital area. In addition, the higher incidence of skin damage on the hip of women may be due to the differences in the nature of skin tissues between the two genders (31-33). Interestingly, skin damage around the ankles was more common in taller patients. This could be possibly due to the unsuitability of operating table length for tall people, which causes their ankles to hang off the bed and puts excess pressure on their skin. Therefore, it is recommended to place a proper pad where the patient's ankles hang off the operating table (34).

\section{CONCLUSION}

The results of this study showed that a large number of patients undergoing spine surgery in the prone position are vulnerable to postoperative skin damage in different body areas. Several factors such as duration of surgery, age, gender, height, weight and BMI can influence the risk of developing these skin damages. Hence, it is recommended to take appropriate preventive measures by placing protective pads at areas that are under pressure during the surgery. Undoubtedly, training staff about the principles of surgical positioning will be effective in reducing the incidence of postoperative skin damage.

\section{ACKNOWLEDGMENTS}

Hereby, the authors would like to express their gratitude to the participants and the authorities of the hospital for their cooperation. We especially thank the Research Deputy of the Alborz University of Medical Sciences for the financial support of this research.

\section{DECLARATIONS \\ Funding}

This study received financial support from the Research Deputy of the Alborz University of Medical Sciences, Iran.

\section{Ethics approvals and consent to participate:}

The study has been approved by the ethics committee of the Alborz University of Medical Science (Ethics code: ABZUMS.REC.1395,43). Informed consent was obtained from all patients prior to participation.

\section{Conflict of interest}

The authors declare that there is no conflict of interest regarding the publication of this article.

\section{REFERENCES}

1. Landi A, Corradetti E, Mancarella C, R D. Prevention of complications related to patient prone positioning during spinal neurosurgical care: a nursing point of view. J Neurosurg Spine. 2013;2:2-4. [DOI:10.4172/2325-9701.1000109]

2. Phillips N. Berry \& Kohn's operating room technique: Elsevier Health Sciences; 2016.

3. Oglesby M, Fineberg SJ, Patel AA, Pelton MA, Singh K. Epidemiological trends in cervical spine surgery for degenerative diseases between 2002 and 2009. Spine.2013;38:1226-32. [DOI:10.1097/BRS.0b013e31828be75d]

4. Benzel EC. Spine Surgery 2-Vol Set E-Book: Techniques, Complication Avoidance, and Management (Expert Consult-Online): Elsevier Health Sciences; 2012.

5. O'Connell MP. Positioning impact on the surgical patient. Nurs Clin N Am.2006;41:173-92. [DOI:10.1016/j.cnur.2006.01.010] 
6. DePasse JM, Palumbo MA, Haque M, Eberson $\mathrm{CP}$, Daniels AH. Complications associated with prone positioning in elective spinal surgery. World journal of orthopedics. 2015;6(3):351. [DOI:10.5312/wjo.v6.i3.351]

7. Shriver MF, Zeer V, Alentado VJ, Mroz TE, Benzel EC, Steinmetz MP. Lumbar spine surgery positioning complications: a systematic review. Neurosurgical focus. 2015;39(4):E16. [DOI:10.3171/2015.7.FOCUS15268]

8. Fu Shaw L, Chang P-C, Lee J-F, Kung H-Y, Tung T-H. Incidence and predicted risk factors of pressure ulcers in surgical patients: experience at a medical center in Taipei, Taiwan. BioMed research international. 2014;2014. [DOI:10.1155/2014/416896]

9. Scott SM. Progress and challenges in perioperative pressure ulcer prevention. Journal of Wound Ostomy \& Continence Nursing. 2015;42(5):480-5.

\section{[DOI:10.1097/WON.0000000000000161]}

10. Kamel I, Barnette R. Positioning patients for spine surgery: Avoiding uncommon positionrelated complications. World J Orthop.2014;5:425. [DOI:10.5312/wjo.v5.i4.425] 11. Nickels TJ, Manlapaz MR, Farag E. Perioperative visual loss after spine surgery. World J Orthop.2014;5:100. [DOI:10.5312/wjo.v5.i2.100]

12. Engels D, Austin M, McNichol L, Fencl J, Gupta S, Kazi H. Pressure ulcers: factors contributing to their development in the OR. AORN j.2016;103:271-81. [DOI:10.1016/j.aorn.2016.01.008]

13. Kumta N, Coyer F, David M. Perioperative factors and pressure ulcer development in postoperative ICU patients: a retrospective review. J Wound Care.2018;27:475-85. [DOI:10.12968/jowc.2018.27.8.475]

14. Webster J, Lister C, Corry J, Holland M, Coleman K, Marquart L. Incidence and Risk Factors for Surgically Acquired Pressure Ulcers. J Wound Ostomy Continence Nurs.2015;42:138-44. [DOI:10.1097/WON.0000000000000092]

15. Cox J. Pressure ulcer development and vasopressor agents in adult critical care patients: a literature review. Ostomy Wound Manage.2013;59:50-4.

16. Cox J. Predictors of pressure ulcers in adult critical care patients. Am J Crit Care.2011;20:364-75.

[DOI:10.4037/ajcc2011934]

17. Lewicki LJ, Mion L, Splane KG, Samstag D, Secic M. Patient risk factors for pressure ulcers during cardiac surgery. AORN j.1997;65:933-42. [DOI:10.1016/S0001-2092(06)62976-1]

18. Schoonhoven L, Defloor T, van der Tweel I, Buskens E, Grypdonck MH. Risk indicators for pressure ulcers during surgery. Appl Nurs Res.2002;15:163-73.

[DOI:10.1053/apnr.2002.34145]

19. Slowikowski GC, Funk M. Factors associated with pressure ulcers in patients in a surgical intensive care unit. J Wound Ostomy Continence Nurs.2010;37:619-26.

[DOI:10.1097/WON.0b013e3181f90a34]

20. Schouchoff B. Pressure ulcer development in the operating room. Crit Care Nurs Q.2002;25:7682. [DOI:10.1097/00002727-200205000-00009]

21. Bulfone G, Marzoli I, Quattrin R, Fabbro C, Palese A. A longitudinal study of the incidence of pressure sores and the associated risks and strategies adopted in Italian operating theatres. $\mathbf{J}$ Perioper Pract.2012;22:50-6, [DOI:10.1177/175045891202200202]

22. Dunn D. Preventing perioperative complications in an older adult. Nursing.2004;34:36-41. [DOI:10.1097/00152193200411000-00039]

23. Dunn D. Age-smart care: Preventing peri operative complications in older adults. Nursing made Incredibly Easy.2006;4:30-9. [DOI:10.1097/00152258-200605000-00006]

24. Fletcher K, Hawkes P, Williams-Rosenthal S, Mariscal CS, Cox BA. Using nurse practitioners to implement best practice care for the elderly during hospitalization: the NICHE journey at the University of Virginia Medical Center. Crit Care Nurs Clin North Am.2017;19:321-37. [DOI:10.1016/j.ccell.2007.05.007]

25. O'brien DD, Shanks AM, Talsma A, Brenner PS, Ramachandran SK. Intraoperative risk factors associated with postoperative pressure ulcers in critically ill patients: a retrospective observational study. Crit Care Med.2014;42:40-7. [DOI:10.1097/CCM.0b013e318298a849]

26. Westhead C. Perioperative nursing management of the elderly patient. ORNAC J.25:34,2007.

27. Cherry C, Moss J. Best practices for preventing hospital-acquired pressure injuries in surgical patients. ACORN.2011;24:16-21.

28. Walton-Geer PS. Prevention of pressure ulcers in the surgical patient. AORN j.2009;89:538-52. [DOI:10.1016/j.aorn.2008.12.022]

29. Bergstrom N, Braden B, Kemp M, Champagne M, Ruby E. Predicting pressure ulcer risk: a multisite study of the predictive validity of 
the Braden Scale. Nurs Res.1998;47:261-9. [DOI:10.1097/00006199-199809000-00005]

30. Pokorny ME, Koldjeski D, Swanson M. Skin care intervention for patients having cardiac surgery. Am J Crit Care.2003;12:535-44.

31. Azzi L, El-Alfy M, Martel C, Labrie F. Gender differences in mouse skin morphology and specific effects of sex steroids and dehydroepiandrosterone. J Invest Dermatol.2005;124:22-7. [DOI:10.1111/j.0022202X.2004.23545.x]

32. Giacomoni PU, Mammone T, Teri M. Genderlinked differences in human skin. J Dermatol Sci.2009;55:144-9.

[DOI:10.1016/j.jdermsci.2009.06.001]

33. Wabnitz PA, Bowie JH, Tyler MJ, Wallace JC, Smith BP. Differences in the skin peptides of the male and female Australian tree frog Litoria splendida: the discovery of the aquatic male sex pheromone splendipherin, together with Phe8 caerulein and a new antibiotic peptide caerin 1.10. Eur J Biochem.2000;267:269-75. [DOI:10.1046/j.1432-1327.2000.01010.x]

34. Burlingame BL. Guideline Implementation: Positioning the Patient. AORN J.2017;106:22737. [DOI:10.1016/j.aorn.2017.07.010 